ИЗВЕСТИЯ АКАДЕМИИ НАУК ЭСТОНСКОП ССР. ТОМ 31 ХИМИЯ. 1982, № 2

\title{
ОБ ИЗМЕНЕНИИ ГРУППОВОГО СОСТАВА САПРОПЕЛЯ ОЗЕРА ЛАХЕПЕРА В ЗАВИСИМОСТИ ОТ ГЛУБИНЫ
}

\author{
(Представил О. Эйзен)
}

Сапропели представляют интерес для практического применения в промышленности (производство строительных материалов, литейное дело), сельском хозяйстве (производство кормов, удобрения) и медицине (бальнеология) $\left[{ }^{1,2}\right]$, а также для теоретических исследований с целью лучшего понимания генезиса твердых ископаемых топлив, точнее сапропелитов и их омешанных разновидностей, в том числе горючих сланцев. В отличие от анализа углей и горючих сланцев анализ сапропелей значительно более сложен, и полученные данные в болышей степени зависят от конкретной методики анализа [3].

Основное внимание в данном исследовании уделено выявлению раннедиагенетических изменений сапропеля оз. Лахепера во времени, а также характеристике данного месторождения в целом.

\section{Экспериментальная часть}

Исходным материалом служил сапропель оз. Лахепера, находящегося в Восточной Эстонии, в $3,5 \mathrm{~km} \mathrm{к} \mathrm{юго-востоку} \mathrm{от} \mathrm{пос.} \mathrm{Алатскиви.} \mathrm{Пло-}$ щадь озера - примерно 100 га. Более подробные данные об озере приведены в [4,5]. Пробы сапропеля отобрал в 1978 г. из скважины L-3 Ю. Паап (Институт геологии АН ЭССР). Предварительные данные об исследовании сапропеля и примененная методика приведены в [5]. Компонентный анализ проведен на основе методики [6]. Bсе операции по выделению компонентов были исчерпывающими и поэтому продолжительными во времени.

\section{Результаты и обсуждение}

Пробы сапропеля изучаемого разреза характеризуются высокой влажностью, которая с увеличением глубины разреза уменьшается от 93,7 до $81,3 \%$ (рис. 1). Гигроскопическая влажность сапропеля (которую высушенные образцы сохраняют на воздухе в обычных лабораторных условиях) для подавляющей части проб колебалась в пределах 9-11\%, что характерно для органических сапропелей (зольность $\leqslant 30 \%$ [7]), несмотря на то, что выход золы изученных проб сапропеля превышает $50 \%$. Уменьшение влажности сапропеля в интервале 4,2-4,7 м связано с увеличением содержания в сапропеле минеральных веществ.

Диагенез мыслят как этап физико-химического уравновешивания сильно обводненного осадка, богатого органическим веществом как живым (бактерии), так и мертвым. Самый ранний процесс уравновешивания - поглощение организмами свободного кислорода иловой воды. Далее, из окислительной среда превращается в восстановительную [8]. Известно, что активность микроорганизмов с увеличением глу- 


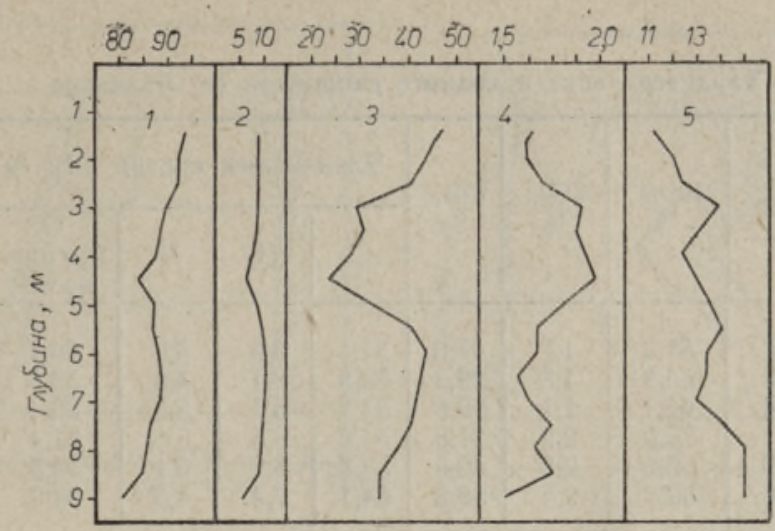

Рнс. 1. Изменения параметров: 1 - влажность; $2-$ гигроскопическая влажность; 3 - содержание органического вещества, \%; 4,5 - атомарные соотношения $\mathrm{H} / \mathrm{C}$ и $\mathrm{C} / \mathrm{N}$ профнля $L-3$ сапропеля оз. Лахепера.

бины профиля донных отложений, как правило, резко падает, что наряду с влиянием фактора времени должно отразиться на составе органического вещества (OB). Что касается элементного состава и атомарного отношения $\mathrm{H} / \mathrm{C}$ (табл. 1 и рис. 1), то здесь каких-либо систематических изменений показателей, кроме увеличения атомарного отношения $\mathrm{C} / \mathrm{N}$, не наблюдается. Но в групповом составе (рис. 2) изменения прослеживаются. Об этом будет сказано ниже.

Традиционное представление экспериментальных данных по групповому анализу имеет один серьезный недостаток: сумма всех определенных групп редко достигает 100\%: 86,2 [7], 67,6 [9] и 55,0\% [10]. Это объясняется тем, что гемицеллюлозой и целлюлозой не исчерпывается состав веществ, выделяемых из сапропеля гидролизом. Поэтому нам кажется более правильным представление данных по групповому составу (табл. 2) в виде первично выделенных из сапропеля веществ.

Содержание битумоида *, обычно именуемого битумом в литературе, касающейся сапропелей, в белорусских сапропелях составляет $3-11$ [?] и $4,3-9,9\left[{ }^{12}\right]$, в латвийских $7-15 \%$ [97, для девяти проб сапропеля, отобранных из различных малых озер Эстонии, $6,2-15,1 \%\left[{ }^{10}\right]$. Для сапропеля оз. Лахепера этот показатель суммы битумоидов А и С составляет 7,6-10,4\% (табл. 2). Количество веществ, гидролизуемых $2 \%$-ной $\mathrm{HCl}$, колеблется в сапропелях в самых широких пределах, и поэтому должно быть принято как один из наиболее характерных для них показателей: 15-52 ['] $], 19,3-51,1$ (в том числе $11,3-35,5 \%$ гемицеллюлозы) [12] и 8-25\% [7]. Выход водорастворимых веществ сапропелей 19-ти озер Латвии колеблется от 2,4 до 3,5 , а гемицеллюлозы от 9,8 до $52,5 \%$ [9]. Те же самые показатели для девяти озер Эстонии колеблются в пределах $1,2-8,4$ и $0,1-14,0 \%$ [ $\left.{ }^{10}\right]$.

Следует указать, что с увеличением глубины сапропеля из оз. Лахепера количество как водорастворимых, так и гидролизуемых $2 \%$-ной $\mathrm{HCl}$ веществ уменьшается соответственно от 4,9 до 3,6 и от 30,6 до $13,4 \%$. Это уменьшение сопровождается увеличением количества веществ, растворимых в 1\%-ном KOH, называемых гуминовыми веществами (гуминовые кислоты + фульвокислоты). Однако их, представляющих собой смесь некромовых и фульвокислот, следовало бы назвать $\left[{ }^{13}\right]$ некромовыми веществами, ибо содержание в них гуминовых и сапропелевых

* Преимущества термина «битумоид» перед термином «битумен» подробно обсуждены Н. Б. Вассоевичем [ $\left.{ }^{11}\right]$. 
Характеристика исходного сапропеля оз. Лахепера

\begin{tabular}{|c|c|c|c|c|c|c|c|c|c|c|}
\hline \multirow{2}{*}{$\begin{array}{c}\text { Глубина } \\
\text { отбора } \\
\text { проб*, } \\
M\end{array}$} & \multirow{2}{*}{$\begin{array}{c}\text { Влаж- } \\
\text { ность, } \\
\%\end{array}$} & \multirow{2}{*}{$\begin{array}{c}\text { Зола, } \\
\%\end{array}$} & \multirow{2}{*}{$\begin{array}{c}\mathrm{CO}_{2}, \\
\%\end{array}$} & \multirow{2}{*}{$\underset{\%}{\mathrm{OB}}$} & \multicolumn{4}{|c|}{ Элементный состав ОВ, \% } & \multicolumn{2}{|c|}{$\begin{array}{l}\text { Aтомарные } \\
\text { отношения }\end{array}$} \\
\hline & & & & & $\mathrm{C}$ & $\mathrm{H}$ & $\mathrm{N}$ & $\begin{array}{c}\mathrm{O} \\
\text { (по раз- } \\
\text { ности) } \\
\end{array}$ & $\mathrm{H} / \mathrm{C}$ & $\mathrm{C} / \mathrm{N}$ \\
\hline $\begin{array}{l}1,28-1,50 \\
2,70-3,20 \\
3,20-3,70 \\
4,20-4,70 \\
6,20-6,70 \\
7,70-8,20\end{array}$ & $\begin{array}{l}93,7 \\
89,9 \\
88,4 \\
84,1 \\
88,7 \\
86,0\end{array}$ & $\begin{array}{l}51,3 \\
68,9 \\
68,1 \\
76,0 \\
55,1 \\
59,3\end{array}$ & $\begin{array}{l}1,7 \\
1,8 \\
1,1 \\
2,2 \\
2,3 \\
2,5\end{array}$ & $\begin{array}{l}47,0 \\
29,3 \\
30,8 \\
21,8 \\
42,6 \\
38,2\end{array}$ & $\begin{array}{l}51,1 \\
53,3 \\
54,2 \\
54,8 \\
53,5 \\
54,1\end{array}$ & $\begin{array}{l}6,9 \\
8,1 \\
8,1 \\
8,5 \\
6,9 \\
7,4\end{array}$ & $\begin{array}{l}5,9 \\
4,8 \\
5,3 \\
5,3 \\
5,1 \\
4,5\end{array}$ & $\begin{array}{l}36,1 \\
33,8 \\
32,4 \\
31,4 \\
34,5 \\
34,0\end{array}$ & $\begin{array}{l}1,62 \\
1,83 \\
1,80 \\
1,86 \\
1,56 \\
1,63\end{array}$ & $\begin{array}{l}10,2 \\
12,9 \\
12,1 \\
12,0 \\
12,4 \\
14,0\end{array}$ \\
\hline
\end{tabular}

* О'т поверхности воды.

таблица 2

Компонентный состав органического вещества сапропеля оз. Лахепера в порядке выделения, \%

\begin{tabular}{|c|c|c|c|c|c|c|c|c|c|c|c|}
\hline \multirow{2}{*}{$\begin{array}{c}\text { Глубина } \\
\text { отбора } \\
\text { проб, } \\
M\end{array}$} & \multirow{2}{*}{ 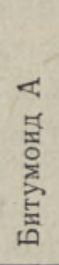 } & \multicolumn{3}{|c|}{$\begin{array}{c}\text { Водорастворимые } \\
\text { вещества }\end{array}$} & \multirow{2}{*}{ 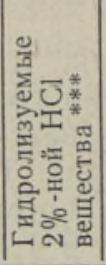 } & \multirow{2}{*}{ 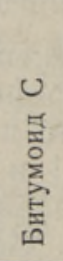 } & \multicolumn{3}{|c|}{$\begin{array}{c}\text { Растворимые в } \\
1 \% \text {-ном КОН } \\
\text { вещества }\end{array}$} & \multirow{2}{*}{ 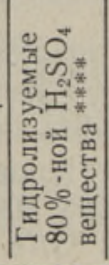 } & \multirow{2}{*}{ 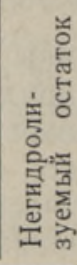 } \\
\hline & & $\begin{array}{l}\stackrel{*}{u} \\
\text { i⿱口 }\end{array}$ & $\begin{array}{l}0 \\
0 \\
8\end{array}$ & 일 & & & 总宫品 & 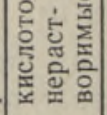 & 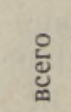 & & \\
\hline $\begin{array}{l}1,28-1,50 \\
2,70-3,20 \\
3,20-3,70 \\
4,20-4,70 \\
6,20-6,70 \\
7,70-8,20\end{array}$ & $\begin{array}{l}7,0 \\
6,5 \\
5,9 \\
5,3 \\
6,1 \\
6,3\end{array}$ & $\begin{array}{l}2,1 \\
2,1 \\
2,0 \\
2,8 \\
1,7 \\
1,6\end{array}$ & $\begin{array}{l}2,8 \\
4,8 \\
2,8 \\
2,7 \\
2,4 \\
2,0\end{array}$ & $\begin{array}{l}4,9 \\
4,8 \\
4,8 \\
5,5 \\
4,1 \\
3,6\end{array}$ & $\begin{array}{l}30,6 \\
26,5 \\
25,1 \\
22,6 \\
19,2 \\
13,4\end{array}$ & $\begin{array}{l}3,0 \\
2,4 \\
2,6 \\
2,3 \\
4,0 \\
4,1\end{array}$ & $\begin{array}{r}10,7 \\
15,8 \\
17,9 \\
9,6 \\
11,0 \\
13,6\end{array}$ & $\begin{array}{l}32,8 \\
28,8 \\
29,9 \\
40,4 \\
41,0 \\
42,3\end{array}$ & $\begin{array}{l}43,5 \\
44,6 \\
47,8 \\
50,0 \\
52,0 \\
55,9\end{array}$ & $\begin{array}{l}2,1 \\
3,4 \\
2,9 \\
1,6 \\
3,8 \\
5,8\end{array}$ & $\begin{array}{r}8,9 \\
11,8 \\
10,8 \\
12,6 \\
10,8 \\
10,8\end{array}$ \\
\hline
\end{tabular}

* Выделяются сахара́, крахмал и др. вещества. ** Выделяются пектиновые и др. вещества. *** Выделяются гемицеллюлоза, азотистые и др. вещества (определены по разности). **** Выделяется целлюлоза и др. вещества (определены по разности).

веществ неизвестно. Выход фульвокислот сапропеля оз. Лахепера, изменяющийся по сложной кривой (рис. 2), компенсируется выходом гуминовых кислот сапропеля так, что их суммарное количество почти плавно увеличивается от 32,8 до $42,3 \%$ с увеличением глубины сапропеля.

Изменение выхода гуминовых веществ по профилю сапропеля объяоняют по-разному. Например, для сапропеля оз. Домжерицкого увеличение выхода гуминовых кислот с 18 в глубине до $36 \%$ на поверхности объясняется развитием торфяника вокруг озера. Увеличение количества гуминовых кислот в донном слое сапропеля оз. Орехово по сравнению с их содержанием в верхнем слое объясняют наличием в нем, так же как и в некоторых других месторождениях, небольшого слоя придонного торфа $\left[{ }^{12}\right]$. Иное толкование дается в $\left[{ }^{14}\right]$, согласно которому определенная роль отводится углеводной части сапропеля в процессе синтеза его гуминовых веществ. Этим и объясняется то, что латвийские сапропели, в которых доминируют гуминовые вещества, в большинстве случаев характеризуются пониженным содержанием углеводной части [ $\left.{ }^{9}\right]$.

Необходимо уточнить, что к настоящему времени еще недостаточно накоплено данных для того, чтобы судить о роли сапропелевого вещества и собственно гумусового вещества при формировании сапропелей. 


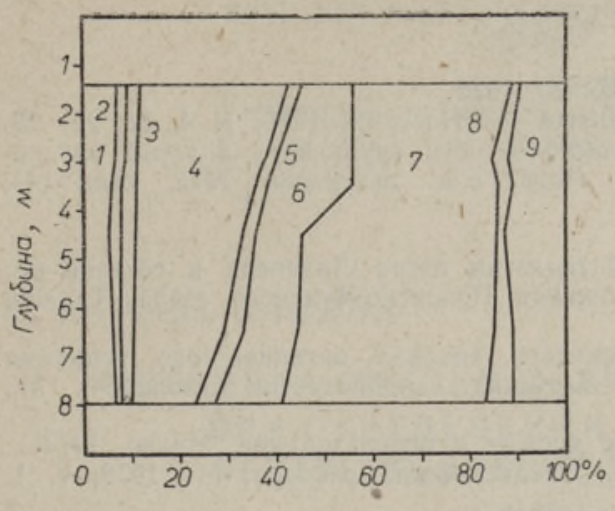

Рис. 2. Распределение органнческих компонентов сапропеля оз. Лахепера: 1 - битумоид А; 2 и 3 - водорастворимые при $55^{\circ}$ и $100^{\circ} \mathrm{C} ; 4$ - гидролизуемые $2 \%$-ной $\mathrm{HCl}$ вещества; 5 битумоид С; 6 - фульвокислоты; 7 гуминовые кислоты; 8 - гидролизуемые $80 \%$-ной $\mathrm{H}_{2} \mathrm{SO}_{4}$ вещества; 9 негидролизуемый остаток.

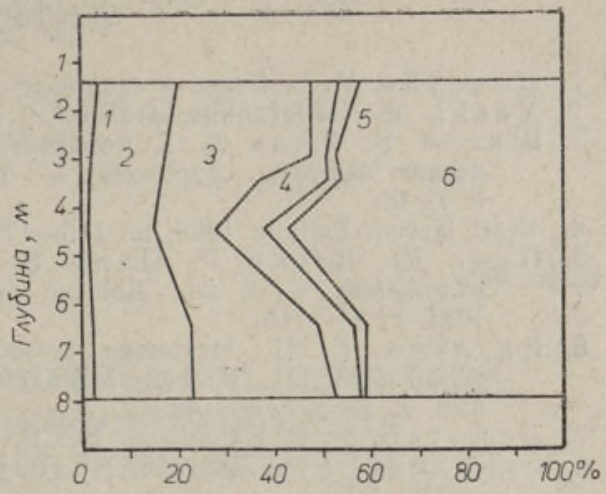

Рис. 3. Содержание минеральных веществ в следующих компонентах сапропеля оз. Лахепера: 1 - водорастворимые; 2 - растворнмые в $\mathrm{HCl} ; 3$ фульвокислоты; 4 - гуминовые кислоты; 5 - растворимые в $\mathrm{H}_{2} \mathrm{SO}_{4} ; 6$ негидролизуемый остаток.

То же самое можно сказать и об исследовании ранних стадий диагенеза озерных сапропелей. Так как в зрелых твердых горючих ископаемых роль гидролизуемых веществ стала очень незначительной, то ощутимое уменышение содержания гидролизуемых веществ по мере увеличения глубины (и возраста) сапропелей можно, по всей вероятности, трактовать как результат раннедиагенетических превращений лепкогидролизуемых веществ в гуминовые вещества сапропеля. Количество последних по отношению к первым увеличивается даже от 1,4 до 4,2. Выход негидролизуемого остатка только незначительно увеличивается с 8,9 до $10,8 \%$, достигая в интервале $4,2-4,7 \mu$ наивысшего значения $12,5 \%$. По выходу негидролизуемого остатка изучаемый сапропель оз. Лахепера занимает одно из последних мест, так как пределы колебания этого показателя для сапропелей составляют от 5 до $55 \%$ [']. Если бы раннедиагенетические потери ОВ сапропеля были существенными, то количество негидролизуемого остатка должно было бы соответственно увеличиваться в результате этих потерь. Укажем также, что большой процент негидролизуемых веществ считается характерным для сапропелей с повышенным содержанием гуминовых веществ [1]. Полученные нами данные по прупповому составу сапропеля оз. Лахепера показывают, что нет обратной зависимости: увеличение количества гуминовых веществ сапропеля не сопровождается увеличением количества негидролизуемого остатка. Так как в ископаемых топливах, ОВ которых сильно преобразовано, негидролизуемая часть - основной компонент этого ОВ, то можно констатировать, что на примере сапропеля оз. Лахепера на фоне изменений в осадконакоплении можно проследить раннедиагенетические изменения ОВ, выражающиеся в превращении легкогидролизуемых веществ в гуминовые вещества сапропеля.

Изменения в распределении минерального вещества по компонентам сапропеля (рис. 3) не подчиняются какой-либо определенной закономерности и непохожи на изменения распределения ОВ. Это в какой-то мере свидетельствует о независимости накопления части минеральных веществ от накопления ОВ сапропеля оз. Лахепера. 
1. Л о по тко М. З. Озера и сапропель. Минск, 1978.

2. Veski, R. Pōllurammu, arstirohtu, telliseid. - Horisont, 1976, N 4, 1k. 22-25.

3. Шкеле В., Удач Л. К методике компонентного группового анализа органических веществ сапропеля. - Тр. Латв. с.-х. академии, 1978, вып. 141, c. $7-9$.

4. Eesti järved. Tallinn, 1968, lk. 176-178.

5. Па а П Ю., Вески Р., Палу В. О геологии озера Лахепера и составе его отложений. - В кн.: Донные отложения Псковско-Чудского озера. Таллин, 1981 , c. $94-115$.

6. К азаков Е. И. Методика компонентного анализа органического вещества сапропелей. - В кн.: Методика изучения сапропелевых отложений. М., вып. 1,1953 , с. $30-48$.

7. Л опотко М. З. Сапропели БССР, их добыча и использование, Минск, 1974.

8. Страхов Н. М. Диагенез. - В кн.: Геологический. словарь. М., 1978, т. 1, c. $221-222$.

9. Бракш Н. А. Сапропелевые отложения и пути их использования. Рига, 1971.

10. С а а р с е Л., К а с к Ю. Компонентный состав органического вещества сапропелей малых озер Эстонии и некоторые пути нх использования. - Изв. АН ЭССР. Геол., 1981, т. 30, № 1, с. 7-11.

11. В ассое в и ч Н. Б. Предисловие. - В кн.: Исследования органического вещества современных и ископаемых осадков. М., 1976, с. $3-24$.

12. Пиддопличко А. П. Озерные отложения Белорусской ССР. Генезис, стратиграфия и некоторые качественные особенности. Минск, 1975.

13. Вески Р. Э., Фоми н а А. С. О термине «гуминовые кислоты». - Хим. тверд. топл., 1978 , № 3 , с. $74-79$.

14. Лукошко Е. С., Р а ковский В. Е. Механизм образования гуминовых веществ в процессе торфообразования. - В кн.: Химия и генезис торфа и сапропеля. Минск, 1962 , с. 23-29.

Ннститут химии

Академии наук Эстонской ССР

Поступила в редакцию 19/VI 1981

Vilja PALU, R. VESKI

\section{LAHEPERA JÄRVE SAPROPEELI GRUPIKOOSTISE MUUTUMINE SUGAVUTI}

Artiklis on esitatud andmeid diageneetilistest muutustest Lahepera järve sapropeeli grupikoostises umbes 7 meetri ulatuses.

\section{Vilja PALU, R. VESKI}

\section{DEPTH-DEPENDENCE OF THE GROUP COMPOSITION OF SAPROPELE OF LAKE LAHEPERA}

This work describes variations in the group composition of sapropele samples from about a seven-meter borehole of small (100 ha) L. Lahepera (East Estonia). On the background of changes in sedimentation it was possible to observe some diagenetic changes. So the ratio of alkali-soluble organic substances of sapropele (the socalled «humic matter») to those hydrolyzing in $2 \% \mathrm{HCl}$ increases from 1.4 to 4.2 with depth, while the yield of nonhydrolyzing sapropele residue remains practically unchanged and low $(8.9 \rightarrow 12.6 \rightarrow 10.8)$. The yield of minor group components varies with depth: bitumoid A $7.0 \rightarrow 5.3 \rightarrow 6.3$, water solubles $4.9 \rightarrow 5.5 \rightarrow 3.6$, bitumoid C $3.0 \rightarrow 2.3 \rightarrow 4.1$ and hydrolyzing compounds in $80 \% \mathrm{H}_{2} \mathrm{SO}_{4} \quad 2.1 \rightarrow 3.4 \rightarrow 1.6 \rightarrow 5.8$. 